\title{
Inhibition of STAT1 sensitizes radioresistant nasopharyngeal carcinoma cell line CNE-2R to radiotherapy
}

\author{
Song Qu ${ }^{1, *}$, Ya Guo ${ }^{1,2, *}$, Shi-Ting Huang ${ }^{1}$ and Xiao-Dong Zhu ${ }^{1}$ \\ ${ }^{1}$ Department of Radiation Oncology, The Affiliated Tumor Hospital of Guangxi Medical University, Cancer Institute of Guangxi \\ Zhuang Autonomous Region, Key Laboratory of High Incidence Tumor Prevention and Treatment Guangxi Medical University, \\ Ministry of Education, Nanning, 530021, PR China \\ ${ }^{2}$ Department of Oncology, The Second Affiliated Hospital of Medical School of Xi'an Jiao Tong University, Xi'an, Shanxi \\ Province, 710004, PR China \\ *These authors contributed equally to this work and are co-first authors
}

Correspondence to: Xiao-Dong Zhu, email: zhuxdonggxmu@126.com

Keywords: nasopharyngeal carcinoma, radioresistance, signal transducer and activator of transcription 1(STAT1), lentivirusmediated RNA interference

Received: September 28, 2016

Accepted: July 13, 2017

Published: July 29, 2017

Copyright: Qu et al. This is an open-access article distributed under the terms of the Creative Commons Attribution License 3.0 (CC BY 3.0), which permits unrestricted use, distribution, and reproduction in any medium, provided the original author and source are credited.

\section{ABSTRACT}

\begin{abstract}
Radioresistance remains a major obstacle for clinicians in the treatment of nasopharyngeal carcinoma (NPC). Others and we have reported that signal transducer and activator of transcription 1 (STAT1) may be as an important gene for resistance to radiation. However, the relationship between STAT1 and radioresistance is still elusive. In this study, by constitutive silencing STAT1 in human radioresistant nasopharyngeal carcinoma CNE-2R cell line, we showed that inhibition of STAT1 enhanced radiosensitivity of CNE-2R. Furthermore, knockdown of STAT1 led to growth suppression and apoptosis promotion in vitro and in vivo. Moreover, cells with low STAT1 expression increased G2/M phase and decreased $S$ phase at 2Gy. These result revealed that knockdown of stat1 expression could sensitizes the CNE-2R to radiotherapy, But the exact mechanism needs to be further clarified.
\end{abstract}

\section{INTRODUCTION}

Nasopharyngeal Carcinoma is the most common cancer in Southeast Asia, especially in south China [1,2]. Radiation has always been the major treatment method for nasopharyngeal carcinoma [3-5]. However, radiation therapy sometimes ineffective as cancer cells may be resistant to radiotherapy $[6,7]$. Thus, it is essential to identify a novel target to reduce radioresistance and enhance the efficacy of radiotherapy for Nasopharyngeal Carcinoma.

Signal transducer and activator of transcription 1 (STAT1) has been identified to be associated with tumor radioresistance [8-10]. A variety of studies have shown that upregulation STAT1 expression is related to radioresistance in many tumors, such as renal carcinoma cells, myeloma cell line, and breast cancer [9-12]. In addition, Hui et al. [13] reported that inhibition the expression of STAT1can improve radiosensitization in renal cell carcinoma cells.

In previous studies, our group found that STAT1 was over-expressed in radioresistant CNE-2R both at mRNA and protein level, and located at the key node of genetic interaction network, which also participated in many bioinformatics pathway $[7,14]$. We speculated that STAT1 might contribute to radioresistance in CNE-2R cells. The currently study was designed to confirm whether STAT1 is correlated with radioresistance of CNE-2R in vivo and in vitro.

\section{RESULTS}

STAT1 knockdown in CNE-2R cells inhibited cell growth in vitro and in vivo

We knocked down the STAT1 expression in CNE$2 \mathrm{R}$ cells by RNAi technology. The efficiency of STAT 1 reduction was confirmed by RT-PCR and Western Blot. As shown in Figure 1A, compared with CNE-2R and CNE-2R-NC cells, the level of STAT1 mRNA in CNE2R-ST cells was decreased by about $81 \%(p<0.05)$, while there were no significant difference between CNE-2R and CNE-2R-NC cells $(p>0.05)$. Figure 1B showed the STAT1 protein level reduced in CNE-2R-ST 
cells compared with CNE-2R and CNE-2R-NC cells, especially the level of STAT1- $\alpha$ protein. Growth curves were then constructed by cell counting. The results from MTT assays showed that cell growth rate of CNE-2RST was slower than CNE-2R-NC $(p<0.05)$, whereas no significant difference was found between $\mathrm{CNE}-2 \mathrm{R}$ and CNE-2R-NC $(p>0.05)$ (Figure 1C). Then we injected an equal number of cells into nude mice. We found that The relative tumor volume of the CNE-2R-ST mice was significantly smaller than that of the control groups $(P<0.05)$, whereas no significant difference was found between the CNE-2R-NC and CNE-2R $(P>$ 0.05 ) (Figure 1D). As shown in Table 1, the tumor weight in the CNE-2R, CNE-2R-NC and CNE-2R-ST were $0.548 \pm 0.08 \mathrm{~g}, 0.4738 \pm 0.043 \mathrm{~g}$, and $0.269 \pm$ $0.035 \mathrm{~g}$ respectively. The results indicated that reduced STAT1 expression in CNE-2R inhibited tumor growth in nude mice.

\section{STAT1 knockdown in CNE-2R cells enhanced apoptosis in vitro and in vivo}

We evaluated the effect of STAT1 knockdown on CNE-2R cells apoptosis in vitro and in vivo. In vitro experiment, the percentage of CNE-2R-ST cells apoptosis significantly increased to $28.97 \pm 1.48 \%$, while there were no significant differences in cell apoptosis between CNE-2R and CNE-2R-NC $(10.95 \pm 3.75 \%, 8.113 \pm 2.38 \%$ respective, $P>0.05$ ) (Figure $2 \mathrm{~A}$ ). In vivo experiment, the apoptosis rate of tumor cells in the CNE-2R-ST group
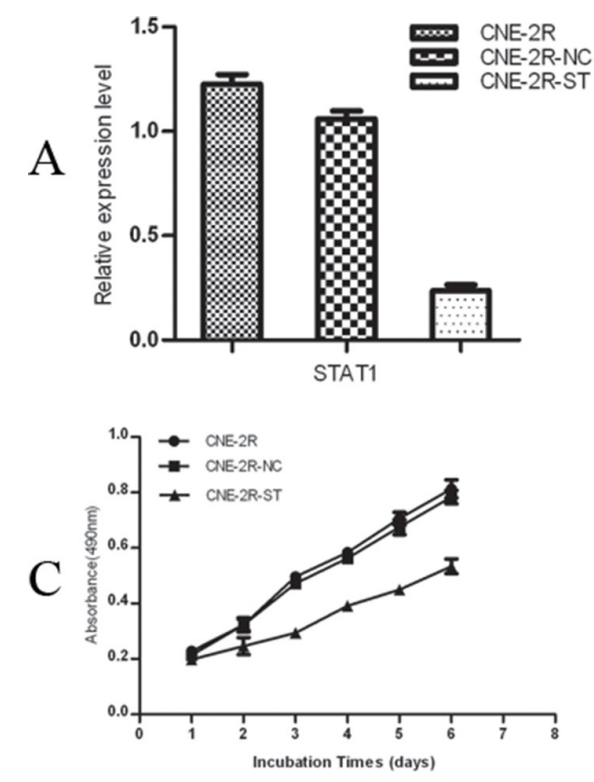

was increased which was more than in the CNE-2R-NC and the CNE-2R group by TUNEL method $(P<0.05)$. (Figure 2B and Table 4)

\section{Enhancing radiosensitivity of CNE-2R cells by RNA interference}

To determine the effect of STAT1 expression on radiosensitivity of $\mathrm{CNE}-2 \mathrm{R}$ cells, colony formation assay was performed with CNE-2R, CNE-2R-NC and CNE-2RST cells. As were shown in Figure 3 and Table 2, CNE2R-ST cells showed a significant decrease in SF2 which was 0.224, whereas CNE-2R-NC and CNE-2R cells, their SF2 were almost similar. The $\alpha / \beta$ ratios in CNE-2R, CNE2R-NC and CNE-2R-ST were 8.432, 11.08, and 28.8 respectively. The results indicated that down-regulation STAT1 could improve radiosensitivity of CNE-2R cells.

\section{The changes of cell cycle induced by lentivirus- mediated RNAi}

To further examine the possible effect of STAT1 on cell cycle of CNE-2R cells, the cell cycle of the cells with or without STAT1 inhibitor was detected. In the absence of irradiation, the cell cycle distribution of these cells had no significant differences. However, upon 2 Gy radiation, a greater accumulation of CNE-2R-ST cells were found in the G2/M phase than those in the control cells, and the percentages of cells in $\mathrm{S}$ phase were decreased $(P<0.05)$ (Figure 4 and Table 3 ).

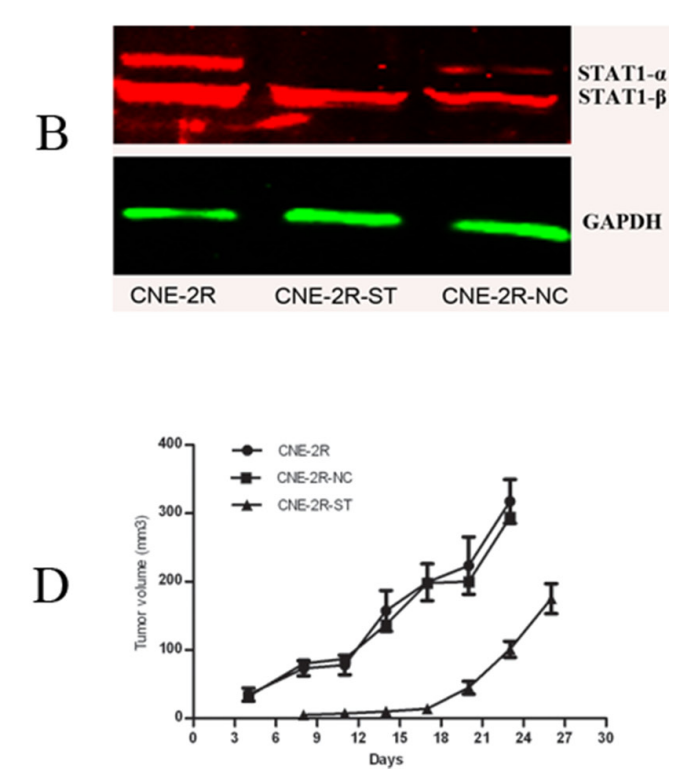

Figure 1: Inhibition of STAT1 decreases cell growth and tumor formation. (A) The efficiency of STAT1 reduction was confirmed by quantitative real-time RT-PCR. The mRNA levels of STAT1 gene expression in CNE-2R, CNE-2R-NC and CNE-2R-ST cells were determined by RT-PCR. STAT1 expression was reduced by about $81 \%$ compared with the control. $P<0.05$. (B) Detection of STAT1 protein expression by western blot. (C) STAT1 promotes CNE-2R cells growth. $3.0 \times 10^{3}$ cells were seeded in each well of 96 -well culture plates and relative cell number was measured everyday for 6 days. $P<0.05$. (D) The tumor volume of each group. CNE-2R, CNE-2R-NC and CNE-2R-ST cells were injected into nude mice, tumor size was monitored every day and was calculated. Weight of the tumor was recorded at the end of the experiment. $P<0.05$. 
Table 1: Tumor formation in nude mice

\begin{tabular}{cc}
\hline Cell types & Tumor weight (g) \\
\hline CNE-2R & $0.548 \pm 0.08 \mathrm{~g}$ \\
CNE-2R-NC & $0.4738 \pm 0.043 \mathrm{~g}$ \\
CNE-2R-ST & $0.269 \pm 0.035 \mathrm{~g}$ \\
\hline
\end{tabular}

CNE-2R, CNE-2R-NC and CNE-2R-ST cells were injected into nude mice, Weight of the tumor was recorded at the end of the experiment.

Table 2: Related parameters of cell survival curve

\begin{tabular}{cccc}
\hline Cell & SF2 & $\boldsymbol{\alpha}$ & $\boldsymbol{\beta}$ \\
\hline CNE-2R & 0.46 & $0.312 \pm 0.043$ & $0.037 \pm 0.017$ \\
CNE-2R-NC & 0.407 & $0.377 \pm 0.068$ & $0.034 \pm 0.029$ \\
CNE-2R-ST & 0.224 & $0.693 \pm 0.036$ & $0.024 \pm 0.022$ \\
\hline
\end{tabular}

CNE-2R, CNE-2R-NC and CNE-2R-ST cells were seeded onto six-well plate and further irradiation with various doses (0-10 Gy). Cells were cultured for 10 day to allow colony formation. The dose-responses were analyzed using a linearquadratic relationship model (LQ model): $\mathrm{SF}=\mathrm{e}^{-(\alpha \mathrm{D}+\beta \mathrm{D} 2)}$, where $\mathrm{D}$ is the single radiation dose and $\mathrm{SF}$ is the surviving fraction at dose D, Alpha and beta are radiobiological parameter.

Table 3: The cell cycle distribution was detected by flow cytometry

\begin{tabular}{lcccc}
\hline Dose (Gy) & Cell cycle phases (x \pm SD, 100\%) & CNE-2R & CNE-2R-NC & CNE-2R-ST \\
\hline \multirow{3}{*}{0 Gy } & G0/G1 (\%) & $56.22 \pm 1.036$ & $52.36 \pm 1.006$ & $57.27 \pm 1.28$ \\
& S (\%) & $22.73 \pm 2.02$ & $25.67 \pm 0.96$ & $25.23 \pm 2.65$ \\
& G2/M (\%) & $21.05 \pm 1.0$ & $21.97 \pm 1.95$ & $17.50 \pm 2.78$ \\
\multirow{2}{*}{ Gy } & G0/G1 (\%) & $55.23 \pm 1.21$ & $56.40 \pm 0.92$ & $55.45 \pm 1.53$ \\
& S (\%) & $19.43 \pm 1.13$ & $18.29 \pm 1.39$ & $9.40 \pm 0.72^{*}$ \\
& G2/M (\%) & $25.34 \pm 0.85$ & $25.31 \pm 0.76$ & $35.16 \pm 0.8^{*}$ \\
\hline
\end{tabular}

We observed the cell cycle distribution of three groups (CNE-2R, CNE-2R-NC and CNE-2R-ST cells) treated with 0 Gy irradiation, There was no obvious difference among these cells, we further studied the effect of STAT1 inhibition on cell cycle at $2 \mathrm{~Gy}$, we found that the percentage of G2/M phase in the CNE-2R-ST cells increased after 2Gy radiation comparing with control cells, and the percentages of cells in $\mathrm{S}$ were decreased $(P<0.05)$.

\section{DISCUSSION}

Nasopharyngeal carcinoma (NPC) is a major malignant tumor of the head and neck region and is endemic in Southeast Asia, especially in Guangdong and Guangxi Province [15]. Radioresistance remains an important factor in relapse and metastasis for Nasopharyngeal carcinoma $[4,6]$. Thus, it is imperative to understand the molecular mechanism of resistance and determine which genes prevent or interfere with resistance.

Signal transducer and activator of transcription 1 (STAT1) was up-regulated in CNE-2R, involved in many significant biological process, and associated with apoptosis and cell cycle genes [6]. Down-regulation of STAT1 expression might increase radiosensitivity of CNE$2 \mathrm{R}$ through inhibiting cell growth, improving apoptotic, and regulating cell cycle. In order to verify the hypothesis, we knocked down the expression of STAT1 in CNE-2R and explored the possible molecular mechanism between STAT1 and radio-resistance.

STAT1 expression has been reported to exhibit tumor suppressor. In renal cancer cells, down-regulation of STAT1 expression induced cell grew more slowly $[9,14]$. Similar result has been obtained in our research. Pitroda et al. [11] revealed that knockdown of stat1 expression could sensitize the head and neck carcinoma cell to radiotherapy. Our data demonstrated that STAT1 inhibition induced radiosensitive in vitro (Figure 3 and Table 1). These results might indicate that STAT1 can improve CNE-2R cell growth, down-regulated STAT1 suppressed cell growth so as to sensitize the CNE-2R cell to radiation therapy.

We evaluated the effect of STAT1 on CNE-2R cell apoptosis in vitro and in vivo. As shown in Figure 2A, 
B, targeting of STAT1 could improve cell apoptosis. It indicated that the expression of STAT1 might suppress cell apoptosis. STAT1 has been reported to mediate proapoptotic or anti-apoptotic signals. It could also regulate apoptosis through a non-transcriptional mechanism by inhibiting the anti-apoptotic protein NF-kappaB [16]. In nu61 tumour, STAT1 might lead to radioresistance by impairing apoptotic [17]. Our data suggested that inhibition of STAT1 expression might increase apoptosis in vitro and in vivo. it means that STAT1 might restrain apoptosis. Our data was in agreement with previous study in that they both confirmed STAT1 may anti-apoptosis. We can infer that STAT1 inhibition induces radiosensitive by promoted apoptosis.

Previous study reported that regulation of cell cycle was crucial to radiation sensitivity. The cell cycle phase also determined a cell's relative radiosensitivity, with cells being most radiosensitive in the $\mathrm{G} 2 / \mathrm{M}$ phase, and least sensitive during the latter part of the $\mathrm{S}$ phase [18]. We then analyzed the cell cycle distribution of un-transfected and stably transfected CNE-2R cells. We found that down-regulation STAT1 expression induced the $\mathrm{S}$ phase was decreased and the G2/M phase was raised at 2 Gy radiation (Figure 4 and Table 3).

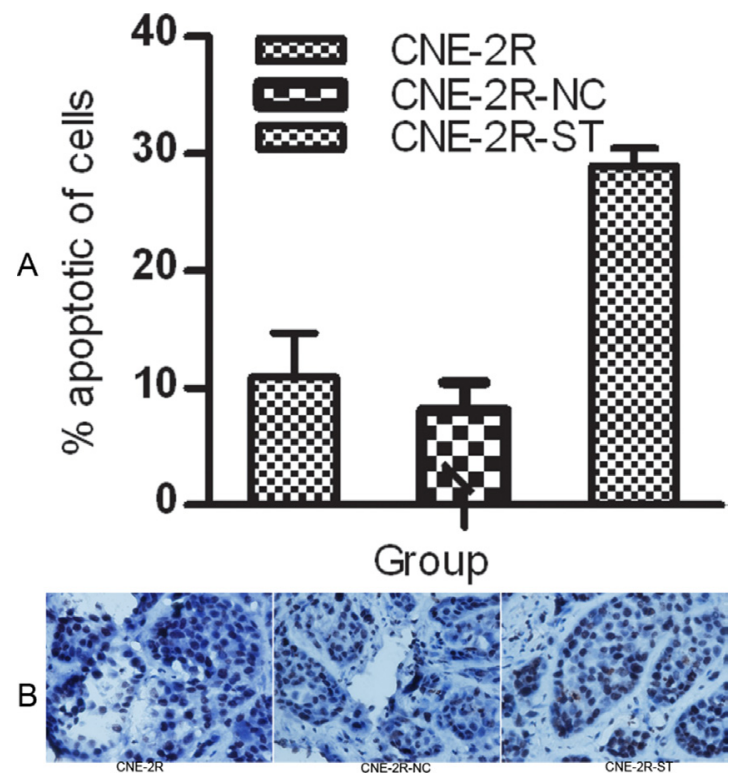

Figure 2: STAT1 inhibition might promote apoptosis. (A) The rate of apoptosis was evaluated by flow cytometry. CNE-2R, CNE2R-NC and CNE-2R-ST cells were cultured for $24 \mathrm{~h}$, then stained with Anneix-V and 7-AAD following the instruction. (B) Tumor cells apoptosis was assessed by TUNEL method. The apoptosis rate of tumor cells in the CNE-2R-ST group was more than the CNE-2R-NC and CNE-2R group (original manification $\times 400),(P<0.05)$.

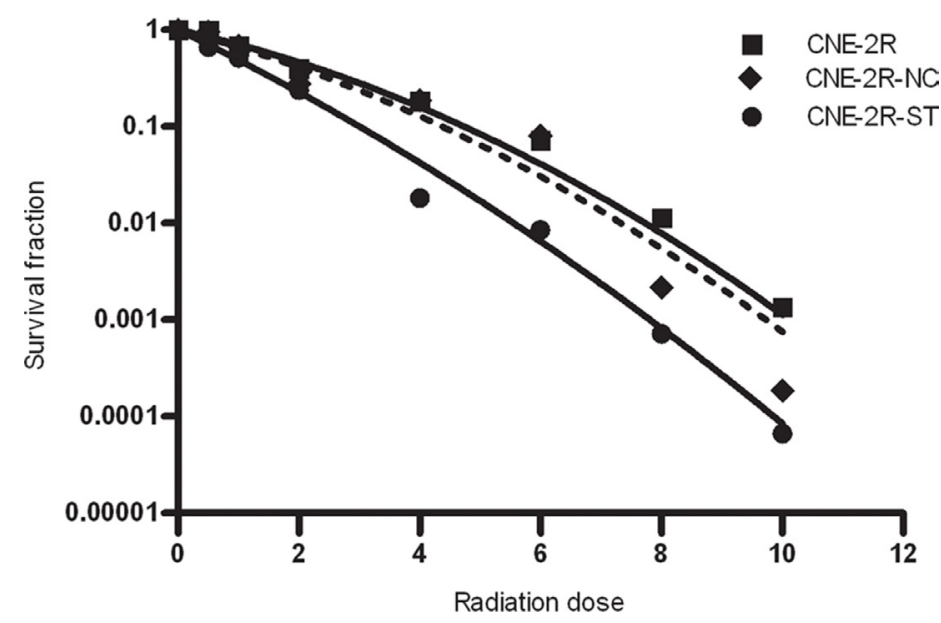

Figure 3: The effect of STAT1 inhibition on radiosensitivity. CNE-2R, CNE-2R-NC and CNE-2R-ST cells were plated onto a six-well plate and were irradiated with X-rays at room temperature. The cells were exposed to doses of 0, 0.5, 1, 2, 4, 6, 8, 10 Gy. After irradiation, cells were cultured for 10 days in $5 \% \mathrm{CO} 2$ atmosphere at $37^{\circ} \mathrm{C}$. 
Table 4: Evaluated the effect of STAT1 on CNE-2R cell apoptosis in vivo

\begin{tabular}{cc}
\hline Group & Cell apoptosis \\
\hline CNE-2R & $10.2 \pm 2.1 \%$ \\
CNE-2R-NC & $5.8 \pm 0.6 \%$ \\
CNE-2R-ST & $6.2 \pm 0.3 \%$ \\
\hline
\end{tabular}

Tumor cell apoptosis was assessed by TUNEL method. We evaluated the effect of STAT1 on CNE-2R cell apoptosis in vivo. As shown in Table 4, the percentage of apoptotic tumor cells in CNE2R, CNE2R-NC and CNE2R-ST was 10.2 $\pm 2.1 \%, 5.8$ $\pm 0.6 \%, 6.2 \pm 0.3 \%$ by the terminal deoxynucleotidyl transferase-mediated dUTP-biotin nick end labeling (TUNEL) method $(P<0.05)$.

Inhibition of STAT1 is convenient cells entering the G2/M phase which induce cells have not enough time to DNA repair [10]. We concluded that down-regulation of STAT1 expression lead to the $\mathrm{S}$ phase was declined and the $\mathrm{G} 2 / \mathrm{M}$ phase was increased, which contributed to improve radiosensitivity of CNE-2R cells. STAT1 might participate in radioresistance through its function in the cell cycle.

In conclusion, STAT1 expression may be correlated with radioreisstance in CNE-2R cells. These result revealed that knockdown of stat1 expression could sensitizes the CNE-2R to radiotherapy. But the exact mechanism needs to be further clarified.

\section{MATERIALS AND METHODS}

\section{Cell culture}

We had successfully established CNE-2R cells in our previous research [7]. It was maintained in RPMI-
1640 medium supplemented with $15 \%$ fetal calf serum. 293T cells was supplied by Cell Bank of Shanghai Institute of Cell Biology, The Cells were cultured in Dulbecco's Modified Eagle's Medium (DMEM). Both of them were cultivitated at $37^{\circ} \mathrm{C}$ in a humidified incubator with 5\% CO2 atmosphere.

\section{Construction of STAT1 lentiviral vectors}

Inverted and self-complementary hairpin DNA oligos targeting STAT1 mRNA and a negative oligonucleotide (NC) were designed and synthesized by Genchem Biotechnology Company (Shanghai, China). The sequences as follows: STAT1-shRNA, sense: 5'-CCGGCTGGAAGATTTACAAGATGAACTCGAG TTCATCTTGTAAATCTTCCAGTTTTTG-3', Negative control shRNA, sense: 5'-CCGGTTCTCCGAAC GTGTCACGTTTCAAGAGAACGTGACACGTTCGGA GAATTTTTG-3'. All above sequences were synthesized, annealed, and ligated into linearized pGCSIL-GFP vector.

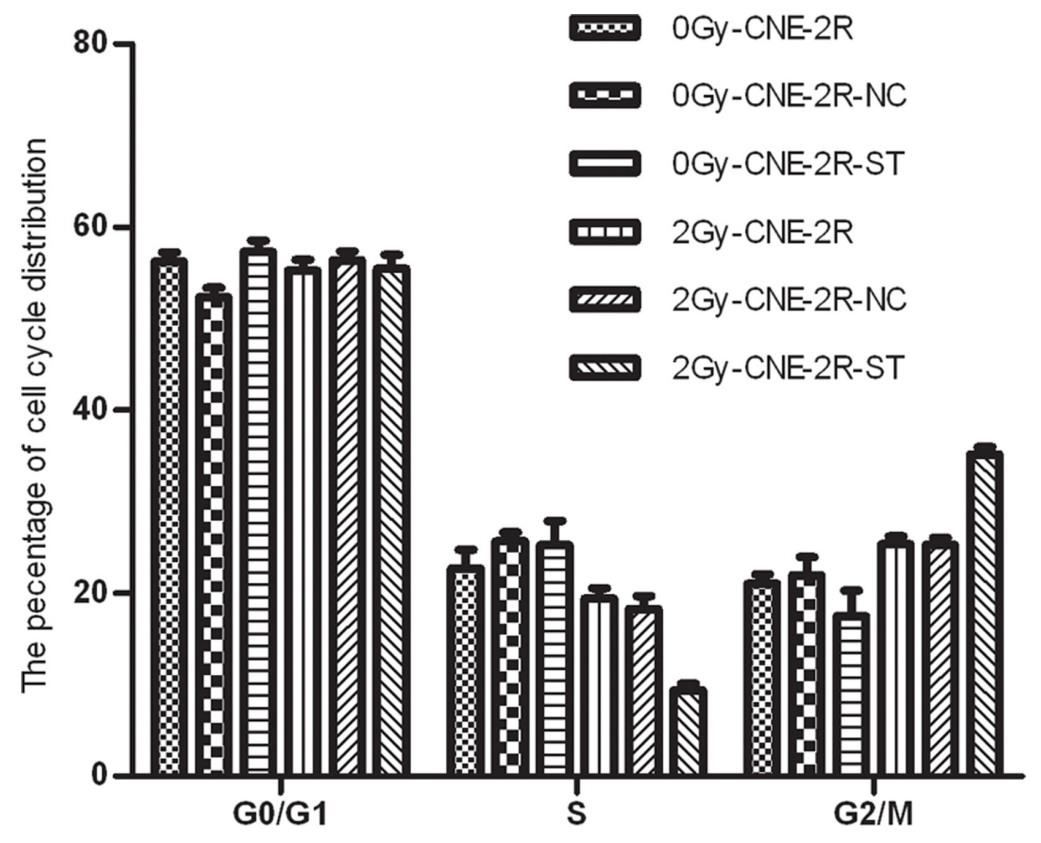

Figure 4: The effect of STAT1 inhibition on cell cycle. The cell cycle distribution of these cells with or without STAT1 inhibitor was detected. The cell cycle distribution of these cells had no obvious difference after radiation at 0 Gy. However, the percentage of G2/M phase in CNE-2R-ST cells increased after radiation doses of $2 \mathrm{~Gy}$ comparing with the control cells. Meanwhile, the percentages of S phase in CNE-2R-ST cells decreased $(P<0.05)$. 
The ligated DNA solution was transformed into E. coli DH5 $\alpha$, and incubated on a Luria Bertani (LB) plate (LB solid medium containing $50 \mathrm{ng} / \mathrm{l}$ ampicillin and $2 \%$ agarose gel) at $37^{\circ} \mathrm{C}$ for $16 \mathrm{~h}$. Positive clones were identified by DNA sequence analysis (Majorbio Biotech Co., Ltd., Shanghai, China). Lentiviral vector DNAs and packaging vectors were then transfected into $293 \mathrm{~T}$ cells. Supernatants containing lentiviruses were harvested $48 \mathrm{~h}$ later after transfection. Then, we performed subsequent purification using ultracentrifugation and the titer of lentiviruses was determined.

\section{Transfection of lentivirus}

CNE-2R was plated in antibiotic-free 1640 at the density of $1 \times 10^{5} /$ well in the 6-wells, when the cell grew to approximately $70-80 \%$ confluence of flask, CNE-2R was transduced with the established lentivirus vector (Multiply of infection, MOI $=10$ ). After $48 \mathrm{~h}$, we observed green fluorescence by Inverted fluorescence microscope. For improving transfection efficiency, the transfected CNE-2R cells was selected by fluorescence activated sorter. CNE-2R cells transfected with lentivirusmediated shRNA targeted STAT1 was named CNE-2RST, transfected with lentivirus-mediated shRNA (NC) was named CNE-2R-NC.

\section{Real-time RT-PCR}

Total RNA was extracted from CNE-2R using Trizol reagent (Invitrogen, cat: 15596026). Reversetranscribed with MLV reverse transcriptase (Invitrogen, cat: 18080044) and random primers. STAT1 primer was designed and synthesis, the length of STAT1 product was $171 \mathrm{bp}$, sense: CCAAAGGAAGCACCAGAGCC; antisense: AGAGCCCACTATCCGAGACACC. Quantitative PCR amplification was done with a $20 \mu \mathrm{l}$ reaction mixture, consisting of $2 \mu \mathrm{l}$ reverse transcription reaction mixture, $0.8 \mu \mathrm{l}$ sense and antisense primers and $9 \mu \mathrm{l}$ PCR master mixture, $7.4 \mu \mathrm{l}$ double steaming water to $20 \mu \mathrm{l}$. The PCR conditions were as follows: initial denaturation at $94^{\circ} \mathrm{C}$ for $3 \mathrm{~min} ; 32$ cycles of denaturation at $94^{\circ} \mathrm{C}$ for $30 \mathrm{~s}$; annealing at $55^{\circ} \mathrm{C}$ for $30 \mathrm{~s}$; elongation at $72^{\circ} \mathrm{C}$ for $30 \mathrm{~s}$, and final extension at $75^{\circ} \mathrm{C}$ for $5 \mathrm{~min}$. The STAT1 expression was normalized using the expression of GAPDH, The $p$-values was calculated based on a Student's $t$-test of the replicate 2(-Delta $\mathrm{Ct}$ ) values for each gene in the control group and experiment group, and $p$ values less than 0.05 were considered statistically significant.

\section{Western blot analysis}

Cells were washed with ice-cold PBS and lysed at $4{ }^{\circ} \mathrm{C}$. The lysaten was centrifuged with $12,000 \mathrm{rpm}$ at $4^{\circ} \mathrm{C}$ for $30 \mathrm{~min}$. The BCA Protein Assay kit (Beyotime, Nanjing, China) was used to determine the protein content in the supernatants. About $30 \mu \mathrm{g}$ of protein was separated on $10 \%$ SDS-PAGE and transferred to polyvinylidene difluoride (PVDF) membranes (Solarbio, PeKing). After being blocked with $5 \%$ nonfat milk for $1 \mathrm{~h}$, the membrane was incubated with different antibodies required at $4^{\circ} \mathrm{C}$ overnight, followed by adding corresponding secondary antibody at room temperature approximately $2 \mathrm{~h}$. The signal was then detected and quantified with Odyssey infrared imaging system (LI-COR Biosciences, Lincoln, NE, USA). STAT1 antibody was obtained from Cell Signaing Technology (9172, Massachusetts, US). The GAPDH primary antibody was purchased from Boster Co. (BA2913, Wuhan, China), and the goat anti-mouse/rabbit IgG secondary antibody was purchased from the KPL Co.

\section{Measurement of cell proliferation by methylthiazoletetrazolium assay}

The cell viability was measured by MTT assay. $3.0 \times 10^{3}$ cells were plated into each well of 96-well culture plates, and relative cell number was measured everyday for 6 days. Each group set up three parallel plates. After incubated $24 \mathrm{~h}$, the medium was aspirated and $20 \mu \mathrm{l}$ of MTT ( $5 \mathrm{mg} / \mathrm{ml})$ was added to the cells. After $4 \mathrm{~h}$ incubation, the media were aspirated and $150 \mu \mathrm{L}$ of dimethyl sulf-oxide was added. Shaking the plates at room temperature for $10 \mathrm{~min}$, Optical densities were determined on a Versamax microplate reader (Thermo, USA) at a wavelength of $490 \mathrm{~nm}$.

\section{Detection apoptosis analysis by flow cytometry}

A total of $1.0 \times 10^{5}$ mock or stably transfected CNE$2 \mathrm{R}$ cells were seeded in the 6 -wells and were cultured for $24 \mathrm{~h}$. Cells were harvested by trypsinization, washed twice with PBS, re-suspended in $500 \mu \mathrm{l} \mathrm{PBS}$, stained with Anneix-V and 7-AAD following the instruction (Becton Dickinson, cat: BD 559763), and then immediately analyzed by flow cytometry. The experiments were performed in triplicate.

\section{In vitro colony formation assay}

For cloning assay, cells were plated onto a six-well plate and were irradiated with X-rays at room temperature. The cells were exposed to doses of $0,0.5,1,2,4,6,8$, $10 \mathrm{~Gy}$. After irradiation, cells were cultured for 10 days in $5 \% \mathrm{CO} 2$ atmosphere at $37^{\circ} \mathrm{C}$. The colonies were fixed with carbinol and stained with $0.1 \%$ Giemsa (Solarbio, cat:51811-82-6). Colonies containing more than 50 cells were scored as survivors. All experiments were performed three times. The survival fraction was calculated as the experimental group numbers of colonies divided by the numbers of cells seeded times plating efficiency. Plating efficiency was calculated as the control group numbers of colonies divided the numbers of cells seeded times 
$100 \%$. The dose-responses were analyzed using a linearquadratic relationship model (LQ model): $\mathrm{SF}=\mathrm{e}^{-(\alpha \mathrm{D}+\beta \mathrm{D} 2)}$, where $\mathrm{D}$ was the single radiation dose and $\mathrm{SF}$ was the surviving fraction at dose D, Alpha and beta were radiobiological parameter. Graphpad Prism 4 software was used to create fit cure.

\section{Cell cycle assay}

Cells were harvested $24 \mathrm{~h}$ after treatment, washed in cold sterile phosphate-buffered saline and ixed with $70 \%$ ethanol at $4^{\circ} \mathrm{C}$ over night. Cells were washed twice with PBS, re-suspended in $500 \mu \mathrm{lBS}$, stained with propidium iodide, and then immediately analyzed by flow cytometry.

\section{Xenograft tumors in nude mice}

Equal numbers of $1.0 \times 10^{7}$ untransfected or stably transfected CNE-2R cells were harvested and subcutaneously injected into 4 to 6 week old BALB/c nude mice (Department of Laboratory Animal, Guang Xi Medical University) which were maintained under pathogen-free conditions. The tumors volume was calculated by the following formula: $\mathrm{V}=0.5 \times \mathrm{A} \times \mathrm{B}^{2}$, where $\mathrm{A}$ was the length and $\mathrm{B}$ was the width of tumor. At 30 days after inoculation, all mice were sacrificed and the weights of tumors were measured at the end of the experiment. For all the experiments, animal handling and experimental procedures were approved by the Animal Experimental Ethics Committee of Guangxi Medical University.

\section{Analyses of xenograft tumor cell apoptosis by TUNEL assay}

A TUNEL assay was performed for all groups according to the manufacturer's protocol (ApopTag S7100; Chemicon International, Billerica, MA). Counting apoptotic cells in 10 arbitrarily selected fields at $\times 400$ magnification under optical microscope (Olympus, Japan). The apoptotic rate (per $\times 400$ microscopic fields) was calculated as number of apoptotic cells $\times 100 /$ total number of cells.

\section{Statistical analysis}

All experiments were performed at least three times. Statistical analysis was performed using SPSS 17.0 software. Data were expressed as the means of three different experiment $\pm \mathrm{SD}$. The Student's $t$-test was used to evaluate the significant difference of two groups of data in all the experiment. $P<0.05$ was thought to be significantly different for two groups.

\section{Author contributions}

Conceived and designed the experiments: Xiao Dong Zhu, Ya Guo. Performed the experiments and
Analyzed the data: Ya Guo, Xiao Dong Zhu, Contributed reagents/materials/analysis tools: Xiao Dong Zhu,Ya Guo, Qu Song. Wrote the paper: Xiao Dong Zhu,Ya Guo, ShiTing Huang.

\section{CONFLICTS OF INTEREST}

None.

\section{FUNDING}

This work was supported by the National Natural Science Foundation of China Grant (No.30860329). The Guangxi Natural Science Foundation (No.0832229) and major research projects of Guangxi universities (No. 201101ZD004).

\section{REFERENCES}

1. Lo AK, Dawson CW, Jin DY, Lo KW. The pathological roles of BART miRNAs in nasopharyngeal carcinoma. J Pathol. 2012; 227:392-403.

2. Sun Y, Yi H, Yang Y, Yu Y, Ouyang Y, Yang F, Xiao Z, Chen Z. Functional characterization of p53 in nasopharyngeal carcinoma by stable shRNA expression. Int J Oncol. 2009; 34:1017-1027.

3. Feng XP, Yi H, Li MY, Li XH, Yi B, Zhang PF, Li C, Peng F, Tang CE, Li JL, Chen ZC, Xiao ZQ. Identification of biomarkers for predicting nasopharyngeal carcinoma response to radiotherapy by proteomics. Cancer Res. 2010; 70: 3450-3462.

4. Wang WJ, Wu SP, Liu JB, Shi YS, Huang X, Zhang QB, Yao KT. MYC Regulation of CHK1 and CHK2 Promotes Radioresistance in a Stem Cell-like Population of Nasopharyngeal Carcinoma Cells. Cancer Res. 2013; 73:1219-1231.

5. Yu S, Zhang R, Liu F, Hu H, Yu S, Wang H. Downregulation of Notch signaling by a gamma-secretase inhibitor enhances the radiosensitivity of nasopharyngeal carcinoma cells. Oncol Rep. 2011; 26:1323-1328.

6. Qu Y, Zhang H, Zhao S, Hong J, Tang C. The effect on radioresistance of manganese superoxide dismutase in nasopharyngeal carcinoma. Oncol Rep. 2010; 23:1005-1011.

7. Guo Y, Zhu XD, Qu S, Li L, Su F, Huang ST, Li DR. Identification of genes involved in radioresistance of nasopharyngeal carcinoma by integrating gene ontology and protein-protein interaction networks. Int J Oncol. 2012; 40:85-92.

8. Fryknas M, Dhar S, Oberg F, Rickardson L, Rydaker M, Göransson H,Gustafsson M, Pettersson U, Nygren P, Larsson R, Isaksson A. STAT1 signaling is associated with acquired crossresistance to doxorubicin and radiation in myeloma cell line. Int J Cancer. 2007; 120:189-195.

9. Zhu HX, Wang ZZ, Xu Q, Zhang Y, Zhai YR, Bai J, Liu M, Hui Z, Xu N. Inhibition of STAT1 sensitizes renal cell 
carcinoma cells to radiotherapy and chemotherapy. Cancer Biol Ther. 2012; 13:401-407.

10. Khodarev NN, Beckett M, Labay E,Darga T, Roizman B, Weichselbaum RR. STAT1 is overexpressed in tumors selected for radioresistance and confers protection from radiation in transduced sensitive cells. PNAS. 2004; 101:1714-1719.10.

11. Pitroda SP, Wakim BT, Sood RF, Beveridge MG, Beckett MA, MacDermed DM, Weichselbaum RR, Khodarev NN. STAT1-dependent expression of energy metabolic pathways links tumour growth and radioresistance to the Warburg effect. BMC Med. 2009; 7-68.

12. Zhan JF, Chen LH, Yuan YW, Xie GZ, Sun AM, Liu Y, Chen ZX. STAT1 promotes radioresistance of CD44+/ CD24(-/low) cells in breast cancer. Exp Biol Med. 2011; 236:418-422.

13. Hui ZG, Tretiakova M, Zhang ZF, Li Y, Wang XZ,Zhu JX, Gao Y, Mai W, Furge K, Qian CN, Amato R, Butler EB, Teh BT, et al. Radiosensitization by inhibiting STAT1 in renal cell carcinoma. Int J Radiat Oncol Biol Phys. 2009; 73:288-295.
14. Zhu XD, Guo Y, Qu S, Li L, Huang ST, Li DY, Zhang W. Radioresistance related genes screened by protein-protein interaction network analysis in nasopharyngeal carcinom. Chin J Radio Med Prot. 2012; 32:20-24.

15. Sun Y, Yi H, Yang Y, Yu Y, Ouyang Y, Yang F, Xiao Z, Chen Z. Functional characterization of p53 in nasopharyngeal carcinoma by stable shRNA expression. Int J Oncol. 2009; 34:1017-1027.

16. Kim HS, Lee MS. STAT1 as a key modulator of cell death. Cell Signal. 2007; 19: 454-465.

17. Efimova EV, Liang H, Pitroda SP, Labay E, Darga TE, Levina V, Lokshin A, Roizman B, Weichselbaum RR, Khodarev NN. Radioresistance of Stat1 over-expressing tumour cells is associated with suppressed apoptotic response to cytotoxic agents and increased IL6-IL8 signalling. Int J Radiat Biol. 2009; 85:642-642.

18. Pawlik TM, Keyomarsi K. Role of cell cycle in mediating sensitivity to radiotherapy. Int J Radiat Oncol Biol Phys. 2004; 59:928-942. 